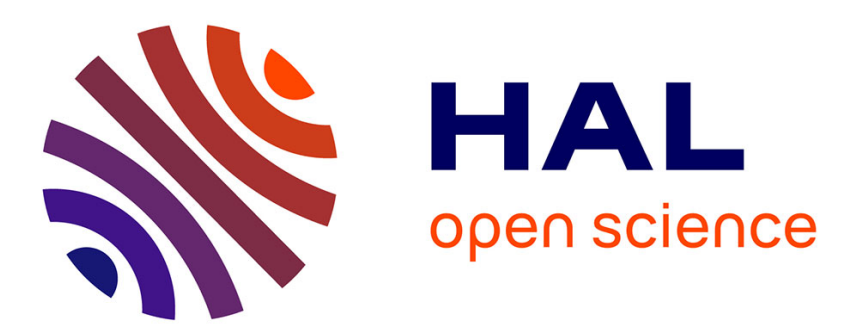

\title{
How to achieve short-term green open access and long-term radical reform of scholarly communication. The BitViews Project as a test case
}

\author{
Manfredi La Manna
}

\section{- To cite this version:}

Manfredi La Manna. How to achieve short-term green open access and long-term radical reform of scholarly communication. The BitViews Project as a test case. ELPUB 2020 24rd edition of the International Conference on Electronic Publishing, Apr 2020, Doha, Qatar. 10.4000/proceedings.elpub.2020.17 . hal-02544856

\section{HAL Id: hal-02544856 https://hal.science/hal-02544856}

Submitted on 16 Apr 2020

HAL is a multi-disciplinary open access archive for the deposit and dissemination of scientific research documents, whether they are published or not. The documents may come from teaching and research institutions in France or abroad, or from public or private research centers.
L'archive ouverte pluridisciplinaire HAL, est destinée au dépôt et à la diffusion de documents scientifiques de niveau recherche, publiés ou non, émanant des établissements d'enseignement et de recherche français ou étrangers, des laboratoires publics ou privés. 


\title{
How to achieve short-term green open access and long-term radical reform of scholarly communication. The BitViews Project as a test case
}

\author{
Manfredi M.A. La Manna
}

\section{Introduction}

The aim of the paper is two-fold:

1. to provide a brief description of, and an interim progress report on, the BitViews project - a low-cost, no-risk, high-return initiative to turn all academic journals green Open Access (henceforth, OA) in the short run through a combination of blockchain technology, the provision of appropriate incentives to authors, and a new crowdfunding mechanism; and

2. to sketch the long-term implications of the key objective of the BitViews project, namely, to de-couple the academy-led peer-review process from the publisher- owned final article (i.e., the Version of Record).

2 The paper argues that both in the short and in the long term the solutions provided by the BitViews project can produce a radical change in the way peer-reviewed knowledge is produced and disseminated worldwide, yielding substantial cost savings and improvements in equity and fairness, especially for readers and researchers in the global South.

In this paper short-term $\mathrm{OA}$ is defined as the free and unrestricted access to the content of peer-reviewed research, i.e., access to the Author's Approved Manuscripts (henceforth AAMs) available on institutional and other repositories. Notice the stress on "short term" and "content". The progress of OA has been, and still is, hampered by the pursuit of the perfect at the expense of the good. Even today, without any structural change to the dysfunctional academic publishing ecosystem it would be possible to deposit $80 \%$ of peer-reviewed articles as OA AAMs, thereby improving 
substantially the status quo. Of course, AAMs are not as beautifully (and expensively!) packaged as the finished article - pagination is different, discoverability is patchy, etc. but (this is the critical fact) they contain $100 \%$ of the peer-reviewed knowledge of the published article.

Before proceeding with the argument, a myth needs to be debunked - that all University and research librarians are equally committed to OA.

There are librarians who are prepared to manage and perpetuate the status quo in which a few oligopolistic publishers exploit researchers, students, and the general public for the benefit of their own shareholders.

There are librarians who are content with minimizing the damage inflicted by these publishers and/or embrace "revenue neutrality" whereby the extortionate revenues from (bundled) subscription charges are kept unchanged but merely re-directed into the publishers' pockets in the form of article processing charges (APCs).

7 There are librarians who use multi-stage multi-agent decision-making processes as an excuse for delaying, or refusing to take, actions that would change scholarly communication for the better and for the many.

Some leaders of learned societies are also likely to be deaf to the message of this paper: I am referring, for example, to those who are "skeptical about the utility of global dissemination of the author accepted manuscript (AAM) via university repositories" and thus, are willing to sacrifice the access to knowledge for countless readers, especially in the global South, because AAMs "lack stable pagination".

These librarians and leaders of learned societies appear to ignore the inconvenient fact that lack of OA can, and does, lead to closed coffins, diminished lives, and untapped talents on a planetary scale. They are not expected to support the BitViews project.

The paper reports on the take-up of the BitViews project by libraries both in the global South and the global North and by national and international agencies.

The concluding section of the paper sketches a possible direction of travel for academic journal publishing in the near future. Huge savings and increased efficiency can flow to the academy from finally dissolving its current one-sided contract with publishers and from reclaiming control and ownership of the peer-review process.

\section{What is BitViews, and why is it a game-changer for OA?}

2 The BitViews Project has been presented at various international conferences (ICADL2018 Hamilton NZ, RLUK2019 London UK, OR2019 Hamburg Germany, Charleston SC USA) and is described in a recent Insights article.

3 The key idea is to use blockchain technology to collect, validate, and disseminate online usage data of AAMs deposited in OA repositories. These data provide the raw material for devising non-citation research impact metrics thus offering authors a personal incentive to increase the visibility of their research by depositing their AAMs (thereby closing a virtuous circle). If successful, BitViews has the potential to turn every academic journal "green" OA at close-to-zero cost.

There can be little doubt that the OA movement has not fulfilled its early promise: after twenty years of efforts not only the percentage of OA articles is only $30 \%$ (and even less 
on quality-adjusted basis), but also the authors of peer-reviewed outputs consistently regard $\mathrm{OA}$ as a non-priority, trumped by prestige, impact factor, and even by preprints. It follows that a rapid route to universal OA is as badly needed as ever.

Even though BitViews is the world's first application to deploy blockchain technology to collect, validate, aggregate, and disseminate online usage data, perhaps its most transformative aspect is not technological, but sociological, in so far as it changes radically the role that individual librarians are required to play to make it succeed: the BitViews project allows individual university libraries to be catalysts for change.

The paper reports on the outcome of the unique mechanism adopted to fund BitViews, whereby individual libraries in the global North directly crowdfund the project in a novel two-stage process and libraries in the global South also play a crucial role.

The paper will provide evidence on the response by national and international associations and agencies.

\section{Open Access is necessary but not sufficient to end knowledge apartheid}

18 It is a sign of both economic myopia and an underdeveloped corporate social responsibility that none of the oligopolistic academic publishers allow individuals and organizations in the global South to gain free and unimpeded access to their paywalled journals. The small cost of foregone subscriptions and APC revenues from the few libraries and authors who can afford them would be more than compensated by both the increased value of the journals in terms of larger readership and the publicrelations benefits flowing from such a philanthropic move.

It would be naïve to expect oligopolistic publishers to forego even a miniscule fraction of their multi-billion annual profits for such a trivial matter as ending the knowledge apartheid that relegates billions of people in the global South to second-class citizens of the world.

What I do expect is that in the developed world, librarians and organizations with an $\mathrm{OA}$ mission stop debating about transformative agreements, metal gradations of $\mathrm{OA}$ (from bronze to platinum), APCs, etc. and instead take direct, effective, and immediate action to stop the economic waste and the unfairness involved in denying access to knowledge to the least privileged section of the world population.

21 The damaging effects of depriving billions of people in the global South of access to peer reviewed research are too well known to require repetition. In this respect any initiative (including BitViews) that enlarges the set of readers of already published research is to be welcome for tackling one aspect of knowledge apartheid.

In my view there is another side of knowledge apartheid that receives far less attention but is as important as access to research: access to the production of peer-reviewed research. I am not referring to the well-rehearsed criticisms of APCs as the means to fund OA, which so blatantly discriminate against potential authors affiliated to resource-poor institutions and therefore damage the publishing potential of researchers in the global South.

Instead, I wish to bring to the fore a subtler but just as corrosive feature of the current subscription-funded, citation-based academic publishing system. Academic publishing 
rewards both authors and publishers by the currency of citations: the former because citations (either directly, as counts, or indirectly, via the impact factor as signal of journal quality) are regarded as the main signal of academic reputation and esteem, the latter because citations, being attached to a commodity (the published article) publishers own, can be monetized by charging more for high impact-factor journals. This simple and incontrovertible fact distorts the production of knowledge in two separate ways, each to the detriment of the welfare of the global South.

First, the dominance of citations provides a powerful disincentive for academics (both in the developed world and in the global South) to engage in research that affects chiefly the global South, irrespective of its potentially large impact on the region. The reason is obvious: in order to be cited in an article, the article has to be published in the first place, but the volume of peer-reviewed articles originating in the global South is very small and its relevance even smaller if articles are quality- (i.e., citation-) weighted.

Second, the large commercial publishers that dominate academic publishing have little interest in fostering global-South journals because of the relatively insignificant resulting revenues (whether coming from subscriptions or from APCs). And even when global-South-based researchers manage to break into high-impact (global-North-based) journals, their articles garner fewer citations than similar articles by better-connected global-North authors.

It is easy to see how a project such as BitViews can contribute not only to solving the problem of access to published knowledge but also to increasing the flow of peerreviewed research aimed at, and produced by, the global South.

BitViews provides an additional token of academic esteem and recognition in the shape of online usage data of AAMs and therefore can track the non-citation impact of research, thereby endowing peer-reviewed AAMs written for or by the global South with validated and robust evidence of its reach beyond paywalls.

In the Insights article, some partial but suggestive evidence is presented showing the effect of replacing citations with views of articles produced by Africa-affiliated authors on the ranking of journals in the field of emergency medicine as recorded in the Scopus/ SciVal database for the period 2014- mid-2019. The results are remarkable: replacing citations with online views/downloads demotes top-tier (mainly paywalled) journals dramatically and conversely mid-ranking journals (mainly OA) climb to 2 nd, $4^{\text {th }}, 5^{\text {th }}, 6^{\text {th }}$ and $7^{\text {th }}$ place.

Imagine the effect of being able to perform similar analyses with validated and auditable data for any discipline for any geographical area and for any time period. We suggest that the evidence thus produced could not be ignored: libraries could make better-informed decisions on which journals are relevant for their readers, researchers could identify which journals enabled them to reach specific readerships, and readers could discover which journals were more significant to their interests and purposes.

\section{Long-term effects of the BitViews Project}

30 This section attempts to forecast a possible direction of travel for academic journal publishing.

31 The theoretical background of BitViews is the hypothesis that the fundamental obstacle to achieving a more efficient and fairer mechanism for producing and disseminating 
peer-reviewed research is the coupling together of the outcome of peer review (the AAM) with post-AAM services into a single commodity - the published article.

The implicit social contract between the academy and publishers whereby the former would let the latter organize both peer review and the (hard copy) publication of research papers broke down in the 1980s and 1990s when a handful of commercial publishers exploited the quasi-monopoly position of each (high-impact) journal and charged libraries subscription prices vastly above cost to the exclusive benefit of their own shareholders.

The time will soon come when the academy realizes that huge savings and increased efficiency can flow from finally dissolving the current one-sided contract with publishers and reclaiming control and ownership of the peer review process. It is worth stressing that a project such as BitViews, by giving additional and independent value to AAMs (as opposed to VoRs), can play a significant, if indirect, role in reshaping the relationship between peer review and academic publishing as explained below.

A rational and efficient mechanism for the production and dissemination of peerreviewed research that exploits the comparative advantage of both the academy and of commercial publishers must necessarily involve two separate stages.

1. Peer review stage: with one essential difference, this stage involves no change compared with the current situation - referees will keep on refereeing (for free), editors will keep making editorial decisions (mainly for free), authors of accepted papers will keep receiving their AAMs. The one essential difference with the status quo is that the small fixed costs of peer review will be incurred by the academy, thereby retaining control (and ownership) of the whole process up to and including the production of AAMs. Notice that universal OA to the content of peer-reviewed research is achieved by default, as AAMs are deposited in one or more IRs as part of the academy-owned peer review process.

2. Post peer review stage: at the end of the first stage the academy is the owner of a product (the AAM) whose value can be increased by the provision of additional services in which commercial publishers have a distinct comparative advantage, from printing and distributing in hard copy to referencing services, etc. Notice the inversion of roles: the academy would switch from being a passive (and exploited) consumer of published articles to supplier of AAMs and correspondingly publishers would be competing with each other for the right to provide additional services that augment the value of AAMs.

It is important not to repeat the same mistakes that have led to the glacial progress of $\mathrm{OA}$ with the re-appropriation of peer review by the academy: simply defining a destination with attractive facilities without spelling out the route(s) that can lead to it is a recipe for failure. And, yet again, the issue of providing appropriate individual incentives to the key players is going to be crucial for the success of the transition.

What follows is a preliminary account of how the many stakeholders in the academic publishing environment can be induced to take beneficial actions by furthering their own objectives.

a. University administrators and executives: the substantial savings in subscription and APCs that would accompany the transfer of ownership of the peer review process from publishers to the academy would provide university finance directors with the wherewithal not only to accommodate the relocation and fixed costs of editorial offices but also to provide financial and career benefits to editors and editorial boards, thereby facilitating the transfer. Even by the most conservative of estimates, the transfer of ownership of peer review from publishers to the academy would generate a substantial surplus, which, in turn, would 
provide the main motivation for University administrators to initiate and manage the switch.

b. Learned societies and associations: it is no secret that some learned societies and associations have failed over the years to take a robust position vis-à-vis publishers to ensure the most efficient and fairest mechanism to produce and disseminate knowledge, effectively taking a (small) share of the publishers' super-normal profits to fund their non-publishing activities. Under the reformed mechanism sketched here they would still be able to do so, but the income stream would come from the cost savings resulting from the transition, from the sale to publishers of the right to add value to AAMs, and from membership fees.

c. Editors, editorial board members, and referees: currently the main agents in the peer review cycle are not remunerated or earn relatively small honoraria. Under a reformed mechanism, their essential contribution to the integrity of science and scholarship can be rewarded both financially and in terms of peer recognition and academic advancement. Notice also that an academy-owned peer review mechanism is better suited to accommodate discipline-specific features of peer review. For example, disciplines and sub-disciplines that currently struggle to receive high-quality and timely reports from referees could introduce appropriate incentives (either financial or reputational) and would be able to levy income- graduated submission fees.

d. Research funders: under the reformed mechanism advocated here, research funders will no longer have to pay APCs and green OA would not have to be mandated (as it would happen by design). The very large resource savings thus generated can be better directed to sustain the peer review infrastructure and, for an initial period, to cover the one-off costs of switching the ownership and control of peer review from publishers to the academy.

e. Foundations/charities with OA missions: I have not been able to collect data on the resources that foundations/charities with OA missions have spent on OA in the last 20 years or so, but I would not be surprised if they amounted to hundreds of millions of US\$ if not more. While some of their efforts have been transformational, for the rest cost-benefit analyses would be rather disappointing, I suspect. In the new landscape of academy-owned peer review, targeted philanthropic grants could play a fundamental role in ensuring a speedy and successful transition. In particular, OA foundations and charities should explode the myth that the online infrastructure supporting peer review (e.g., manuscript processing software) is expensive to build and to maintain. Of course, as long as it is owned by private equity companies and used as a cash cow, there is a strong incentive to gold-plate it and charge correspondingly inflated prices.

Instead, foundations and charities could commission and release as open-source discipline-specific manuscript processing software at a fraction of the cost currently burdening the academy. More generally they could facilitate the one-off costs of flipping peer review from publisher- to academy-ownership.

The transfer of ownership and control of peer review may take different forms and at different speeds, depending on the specifics of the journals and disciplines affected:

a. Journals published commercially on behalf of learned societies can switch to academyownership at the next contract renewal date;

b. Editors and editorial boards can migrate from publisher-owned journals to academy-owned ones;

c. New academy-owned journals can be set up as direct competitors (i.e., upholding the same or higher acceptance standards) of publisher-owned ones.

It is easy to see that this more rational and efficient mechanism would release a substantial amount of resources currently being wasted on gold-plated publishing 
services or being transferred to the shareholders of commercial publishers. Even a small fraction of the savings thus gained would be sufficient to fund the switch from publisher- to academy-ownership of the peer review process.

It would be naïve if not irresponsible to underplay the likely response by commercial publishers to a reform that would substantially reduce their market power and their super-normal profits. Similarly, those learned societies who benefit from the current arrangement can be expected to oppose any change that challenges the status quo. The power of attraction of high-impact, long-established journals will have to be countered by an equally strong centrifugal force.

41 A key role is going to played, again, by the main direct beneficiaries of the switch of ownership of peer review from the publishers to the academy, namely the organizations (Universities, research funders, charities) that foot the current bill of over US $\$ 10$ billion p.a. in subscription charges and APCs. The range of measures that these organizations could take to facilitate the switch is wide and would include:

1. Positively discriminating in favour of academy-owned journals (notice that there would be no dilution of peer review standards, as these would be set, monitored, and enforced by the academy). For example, for an initial period of 3-5 years, articles published in new academyowned journals could be given double weight compared to their commercially-owned counterparts;

2. For an initial period of 3-5 years, research funders could add a premium to articles published in academy-owned journals to be paid directly to these journals;

3. DORA-endorsing Universities are empowered to make judgements about the quality of published articles based not on impact-factor metrics, but on the public and transparent peer review criteria of academy-owned journals.

Historians of scientific publishing will recognize the similarities between the two-phase reform proposed in this paper and the relationship between learned societies and publishers/printers that had endured since Oldenburg's days up to the 1950s. Then the peer review process was firmly in the hands of learned societies who would put to tender (admittedly not very frequently) the contracts to produce their printed journals. The quality of peer review was guaranteed by the admission criteria for membership of the society (being male, white, and upper-middle class conferred a distinct advantage). of course, in the online age, there is no reason to repeat the mistakes of the past and every reason to enforce rules and conventions ensuring that peer review is carried out in ways that do not discriminate on grounds of gender, age, affiliation, nationality, etc.

Finally, it is worth stressing the benefits that a more rational academic publishing ecosystem would produce for the global South, in addition, of course, to the planetwide benefit of universal OA. In the post-BitViews environment envisaged here, there is no need for APCs and thus one powerful force for discrimination is eliminated altogether. of course, in a post-BitViews world, economic inequality between the global South and the global North will still exist and libraries and institutions in the global South will have fewer resources to buy additional non-essential post-peer-review services, but they will be guaranteed equal access both to the content of published research and to the means of dissemination of new research. Knowledge apartheid would end. 


\section{BIBLIOGRAPHY}

Akre Olof et al., "Differences in citation rates by country of origin for papers published in topranked medical journals: do they reflect inequalities in access to publication?", J Epidemiol Community Health 65, no. 2, 2011 pp. 119-23. DOI: 10.1136/jech.2009.088690.

Johnson, Rob et al. The STM Report, 2018, stm-assoc.org/2018_10_04_STM_Report_2018.pdf. Lamanna, Camillo, and Manfredi La Manna. "The Fundamental Problem Blocking Open Access and How to Overcome It: The Bitviews Project." Insights 32, no. 1, 2019. DOI: doi.org/10.1629/ uksg. 488 .

Margot Finn. "President of the Royal Historical Society, interviewed by Karin Wulf in The Scholarly Kitchen", 21 Nov. 2019: scholarlykitchen.sspnet.org/2019/11/21/historians-respond-toplan-s-open-access-vs-oa-policies-redux/?informz=1.

Moxham, Noah, and Aileen Fyfe, "The Royal Society and the prehistory of peer review, 1665-1965”, The Historical Journal, 61, no. 4, 2018, pp. 863-889. DOI: 10.1017/S0018246X17000334.

Niles, Meredith T., et al. "Why We Publish Where We Do: Faculty Publishing Values and Their Relationship to Review, Promotion and Tenure Expectations.” BioRxiv, Jan. 2019. doi: $10.1101 / 706622$.

ScholarOne, a leading manuscript processing package, is produced by Clarivate owned since 2016 by the Canadian private equity firm Onex Corp and by Baring Private Equity Asia.

\section{ABSTRACTS}

The Open Access movement has reached adulthood, but not maturity: fewer than one-third of newly-published peer-reviewed articles are available open access (OA) and progress widening OA has stalled. Scores of uncoordinated initiatives try to achieve universal OA, but academic journal publishing is still dominated by a handful of powerful commercial publishers. Individual authors show little interest in OA and indeed have to be mandated (see the UK REF or Plan S) to release their research on OA. The BitViews Project is a low-cost, no-risk, high-return initiative to turn all academic journals «green» through a combination of blockchain technology, provision of appropriate incentives to authors, and a new crowdfunding mechanism. The project is predicated on the active participation of individual libraries taking direct action. The paper will provide an interim report on the progress of the project and an account of how libraries and their various associations (both in the global South and in the global North) have reacted to the project. The concluding section of the paper sketches a possible direction for academic journal publishing in the near future. Huge savings and increased efficiency can flow to the academy from finally dissolving its current one-sided contract with publishers and from reclaiming control of the peer-review process. Practical and incentive-based suggestions are proposed for the transition from publisher-owned to academy-owned peer review.

\section{INDEX}

Keywords: open access, BitViews, blockchain, online usage data, peer review, author's approved manuscript, library activism, conditional crowdfunding. 
AUTHOR

\section{MANFREDI M.A. LA MANNA}

School of Economics and Finance, University of St Andrews, UK, mlm@st-and.ac.uk 